\title{
Head-Directional Tuning and Theta Modulation of Anatomically Identified Neurons in the Presubiculum
}

\author{
DJohn J. Tukker, Qiusong Tang, Andrea Burgalossi, and Michael Brecht \\ Bernstein Center for Computational Neuroscience, Humboldt University of Berlin, 10115 Berlin, Germany
}

\begin{abstract}
The presubiculum provides a major input to the medial entorhinal cortex (MEC) and contains cells that encode for the animal's head direction (HD), as well as other cells likely to be important for navigation and memory, including grid cells. To understand the mechanisms underlying HD cell firing and its effects on other parts of the circuit, it is important to determine the anatomical identity of these functionally defined cells. Therefore, we juxtacellularly recorded single cells in the presubiculum in freely moving rats, finding two classes of cells based on firing patterns and juxtacellular labeling (of a subset). Regular-firing cells had the anatomical characteristics of pyramidal cells and included most recorded HD cells. Therefore, HD cells are likely to be excitatory pyramidal cells. For one HD cell, we could follow an axon projecting directly to the MEC. Fast-spiking (FS) cells had the anatomical characteristics of interneurons and displayed weak HD tuning. Furthermore, FS cells displayed a surprising lack of theta-rhythmic firing, in strong contrast to the FS cells that we recorded in the MEC. Overall, we show that HD cells in the presubiculum are pyramidal cells, with FS interneurons only showing weak HD tuning; therefore, MEC may receive an excitatory HD input, as previously assumed by many models. The lack of theta rhythmicity in FS interneurons suggests that different mechanisms may underlie theta in different parts of the hippocampal formation.
\end{abstract}

Key words: head direction; juxtacellular; presubiculum; theta

Significance Statement

In freely moving rats, we recorded and labeled single neurons in the presubiculum, an area providing one of the major inputs to the medial entorhinal cortex and part of a network involved in spatial navigation and memory. Post hoc identification of labeled cells showed that (fast-spiking, FS) interneurons and pyramidal cells in the presubiculum can be distinguished based on physiological criteria. We found that both moderately and strongly tuned head-direction (HD) cells are pyramidal cells and therefore likely to provide an excitatory HD input to the entorhinal cortex. FS interneurons were weakly head directional and, surprisingly, showed no theta-rhythmic firing. Therefore, the presubiculum appears to encode HD information via excitatory pyramidal cells, possibly also involving FS interneurons, without using a theta-rhythmic temporal code.

\section{Introduction}

The representation of space in the hippocampal formation depends in part on the presubiculum, which provides a major input to the medial entorhinal cortex (MEC; Kerr et al., 2007), and

Received Feb. 18, 2015; revised Aug. 30, 2015; accepted 0ct. 10, 2015.

Author contributions: J.J.T. and M.B. designed research; J.J.T., Q.T., and A.B. performed research; J.J.T., Q.T., and A.B. analyzed data; J.J.T. and M.B. wrote the paper.

This work was supported by Humboldt Universität zu Berlin, Bernstein Center for Computational Neuroscience Berlin (German Federal Ministry of Education and Research, Förderkennzeichen Grant 01GQ1001A), NeuroCure, the Neuro-Behavior European Research Council, and the Deutsche Forschungsgemeinschaft (Gottfried Wilhelm Leibniz Prize). We thank M. von Heimendahl, C. Ebbesen, C. Boehm, D. Spicher, J. Steger, and U. Schneewei $\beta$.

The authors declare no competing financial interests.

Correspondence should be addressed to either Michael Brecht or John J. Tukker, Charité Universitätsmedizin

Berlin, Charité Crossover NWFZ Campus Mitte, Virchowweg 6-Charitéplatz 1, 10117 Berlin, Germany, E-mail: michael.brecht@bccn-berlin.de or john.tukker@charite.de.

A. Burgalossi's present address: Werner Reichardt Centre for Integrative Neuroscience, 72076 Tübingen, Germany.

DOI:10.1523/JNEUROSCI.0685-15.2015

Copyright $\odot 2015$ the authors $\quad 0270-6474 / 15 / 3515391-05 \$ 15.00 / 0$ contains neurons that encode the animal's head direction, known as HD cells (Taube et al., 1990), in addition to a number of other spatially modulated cell types including grid cells (Boccara et al., 2010). The identity and connectivity of these cells remain unclear, making it difficult to understand their precise role in the circuitry underlying spatial navigation and memory.

Many models of grid cell firing assume that the HD cells may provide an excitatory input related to the heading of the animal (but see Raudies et al., 2014) and, indeed, it was shown recently that grid cell firing depends on an intact HD cell network in the thalamus (Winter et al., 2015), although the precise pathways remain unclear. More generally, the role of inhibition in the presubiculum remains largely unexplored despite its potential importance for attractor models (Knierim and Zhang, 2012), which are likely to be relevant for the HD system (Peyrache et al., 2015), and theta oscillations, which play an important role in the temporal organization of spatial information (Buzsáki and Moser, 2013). 
In this study, we aimed to elucidate the HD tuning and thetarhythmicity of anatomically identified pyramidal cells and interneurons in the presubiculum by performing juxtacellular recordings in freely moving rats.

\section{Materials and Methods}

Procedures. All experimental procedures were performed according to German guidelines on animal welfare. Male Wistar rats $(n=47$; weights $\sim 150-250$ g) were recorded in the dark phase of a $12 \mathrm{~h}$ light/ $12 \mathrm{~h}$ dark schedule. Approximately one week before the first recording, each rat received a head implant, including a post for head fixation, under ketamine/xylazine anesthesia (100 and $5 \mathrm{mg} / \mathrm{kg}$, i.p., respectively) using procedures described previously (Tang et al., 2014). After at least $2 \mathrm{~d}$ to recover, rats were food restricted ( $>90 \%$ of ad libitum body weight) as they learned to forage for chocolate pellets for 3-5 d (1-2 daily 15-20 min sessions). Experiments were performed in a square arena $(70 \times 70 \mathrm{~cm}, 30$ $\mathrm{cm}$ high, black, with white cue card on one wall) or on a platform $(25 \times$ $30 \mathrm{~cm}, 30 \mathrm{~cm}$ high, white) placed at the center of the arena; in addition, the laboratory contained many distal cues.

A craniotomy $(\sim 1 \times 1 \mathrm{~mm}$; AP: at lambda, ML: 3-4 mm, left hemisphere) and durectomy were performed under isoflurane anesthesia (1-3\%), after which animals could recover for at least 3-4 h. After head fixation (sometimes preceded by a subcutaneous injection of lidocaine in the dorsal neck region, observed to minimize head shaking after release; Tang et al., 2014), a glass pipette (3-6 M $\Omega$ ) filled with extracellular Ringer's solution containing the following (in $\mathrm{mm}$ ): $\mathrm{NaCl} \mathrm{135,} \mathrm{KCl} 5.4$, HEPES 5, $\mathrm{CaCl} 2$ 1.8, and $\mathrm{MgCl} 2$ 1, pH 7.2, as well as neurobiotin (1-2\%), was advanced into the brain and agarose ( $4-5 \%$ in Ringer's) was applied. The juxtacellular signal was amplified (ELC-03XS; NPI Electronic) and sampled at $20 \mathrm{kHz}$ (LIH 1600; HEKA Electronic). After the rat was released and placed into the arena, small negative pulses were used to monitor resistance at the pipette tip (increases indicated potential cells). The animal's location and HD were tracked at $25 \mathrm{~Hz}$ (Digital Lynx; Neuralynx) using two head-mounted LEDs. Most cells were lost due to mechanical disturbances; otherwise, we typically terminated recordings after $2-3 \mathrm{~min}$ and attempted juxtacellular labeling. The MEC recordings tended to be longer.

Animals were killed via anesthetic overdose and perfused transcardially $(\sim 100 \mathrm{ml}$ of $0.1 \mathrm{M}$ phosphate buffer, followed by $150 \mathrm{ml}$ of $4 \%$ paraformaldehyde), typically within 20-30 min after labeling. In some cases, repeated recording attempts were made (maximum of 5 sessions over 1-2 weeks), applying mitomycin on the craniotomy after each session and sealing it with silicone.

For four cells, we used a different protocol, described previously in detail (Herfst et al., 2012). In these cases, the rats were not habituated to the arena and the cells were first labeled under anesthesia (intraperitoneal) consisting of a mixture of medetomidine $(225 \mu \mathrm{g} / \mathrm{kg})$, midazolam (6 $\mathrm{mg} / \mathrm{kg}$ ), and fentanyl $(7.5 \mu \mathrm{g} / \mathrm{kg})$, which was then antagonized (subcutaneous) with a mixture of atipamezole $(1 \mathrm{mg} / \mathrm{kg})$, flumazenil $(600 \mu \mathrm{g} / \mathrm{kg})$, and naloxone $(180 \mu \mathrm{g} / \mathrm{kg})$ so that the animals quickly recovered and spontaneously explored the arena.

After perfusion, the brain was removed and left in fixative overnight. Sections $(70-100 \mu \mathrm{m})$ were cut on a vibratome, either sagittally or at an angle of 40-50 degrees relative to the sagittal plane perpendicular to the coronal plane. The location of unidentified cells was confirmed by identification of the track (in some cases using DiI applied to the pipette) and/or (extrapolation from) labeling sites of other recovered cells. Visualization of neurobiotin-filled cells and immunohistochemical staining were performed as described previously (Ray et al., 2014) using streptavidin (1:1000) conjugated to Alexa Fluor 488 or DyLight 549, primary antibodies against parvalbumin (1:5000, mouse monoclonal; Swant 235; Schwaller et al., 1999) and secondary antibodies (1:400) with the fluorophores Alexa Fluor 488 or 546.

Data analysis. This study includes only recordings for which we could record for at least $1 \mathrm{~min}$ or $100 \mathrm{APs}$. We used a manually set threshold and principal component analysis to isolate spikes from recording artifacts. Cell classification was based on spike width ( $3 \mathrm{~ms}$ window) and firing frequency during rat movement $(>2 \mathrm{~cm} / \mathrm{s}$, averaged across a 600 ms rectangular sliding window). Spike width was defined as the time between the first prepeak rise and the first posttrough rise above a threshold (mean baseline power plus five times the SD).

Fast-spiking (FS) cells were defined conservatively, using the parameters from three identified cells as constraints: spike width $<0.875 \mathrm{~ms}$ and moving firing frequency $>10 \mathrm{~Hz}$. Regular-spiking (RS) cells were defined as all cells with wider APs or lower firing frequency.

To quantify HD tuning, we divided the number of spikes by the occupancy for each HD ( $n=36$ bins). The HD index (HDI) of a cell was computed only for cells in which all bins were visited at least once and was defined as the average Rayleigh vector over all bins; that is, for each bin, a vector was created representing the firing rate for that bin and the vector sum was calculated and divided by the overall summed firing rate over all bins. Significance was evaluated with a shuffling test (1000 shuffles consisting of random time shifts of the spike train as a whole). Note that the shuffling procedure indicated nonsignificance even for some relatively high HDI values, namely in those cases in which the HDI values could reflect a considerably skewed occupancy distribution. For recordings in which each HD bin was sampled in each half of the recording, we quantified the stability of the HD tuning by generating separate tuning curves for the first and second half of the recording time and calculating Pearson's linear correlation coefficient. To evaluate bimodality, we used Hartigan's dip statistic (Hartigan and Hartigan, 1985) implemented in MATLAB (F. Mechler; http://nicprice.net/diptest/). The modulation of firing rate by running speed was analyzed as described by Sun et al. (2015). A speed index was defined as the ratio $N$ of APs fired during fast running periods $(>3 \mathrm{~cm} / \mathrm{s})$ relative to APs fired during all running periods $(>1 \mathrm{~cm} / \mathrm{s})$, divided by the ratio $T$ of time spent during fast running periods relative to time spent during all running periods. Significance was determined by comparing $N$ and $T$ using a $\chi^{2}$ test (with FDR correction).

Theta analysis was performed for all recordings in which the animals moved at $>2 \mathrm{~cm} / \mathrm{s}$ for at least $10 \mathrm{~s}$ in continuous epochs each lasting at least $0.5 \mathrm{~s}$ and fired at least $100 \mathrm{APs}$ in this time. We used publicly available MATLAB scripts (https://github.com/jrclimer/mle_rhythmicity) to calculate a theta index (Yartsev et al., 2011) from the spike train's autocorrelation function (10 ms bins), as well as the magnitude $a$ of rhythmic modulation derived from a maximum likelihood estimation (MLE) of a parametric model of the distribution of lags between spikes (range 0-0.5 s), where $a$ varies from 0 (no rhythmicity) to 1 (maximal rhythmicity) and confidence intervals for $a$ were computed by refitting the model keeping all parameters except $a$ fixed (Climer et al., 2015).

\section{Results}

We juxtacellularly recorded single neurons in the presubiculum of rats as they foraged for chocolate pellets in an open arena, finding that neurons discharged either in an RS (Fig. $1 A, B$ ) or FS firing pattern (Fig. 1C,D). These two populations could be well separated based on the spike width and firing rate while the rats moved (Fig. 1E). Importantly, we confirmed this classification in 15 anatomically identified cells based on immunohistochemical and/or morphological analysis.

The firing of several RS cells was strongly modulated by the animal's HD (Fig. 2A,B), fitting the description of classical HD cells (Taube et al., 1990). These cells typically had a pyramidal-like morphology with spiny dendrites spanning all layers including a prominent branching in layer 1, which contains axonal projections from several thalamic nuclei (van Groen and Wyss, 1990a, 1990b) with a large number of sharply tuned HD cells (Taube, 1995). We also observed twice a main axon from a layer 3 RS cell projecting ventrally toward the MEC, which could be traced in one case to the deep layers of the MEC (Fig. 2A), providing the first evidence that at least a subset of HD cells project to the MEC.

Although many recorded RS cells showed sharp HD tuning, we also observed many cells with broader tuning that was still statistically significant (Fig. 2C). We quantified HD tuning by calculating an HDI (see Materials and Methods) for all cells in 

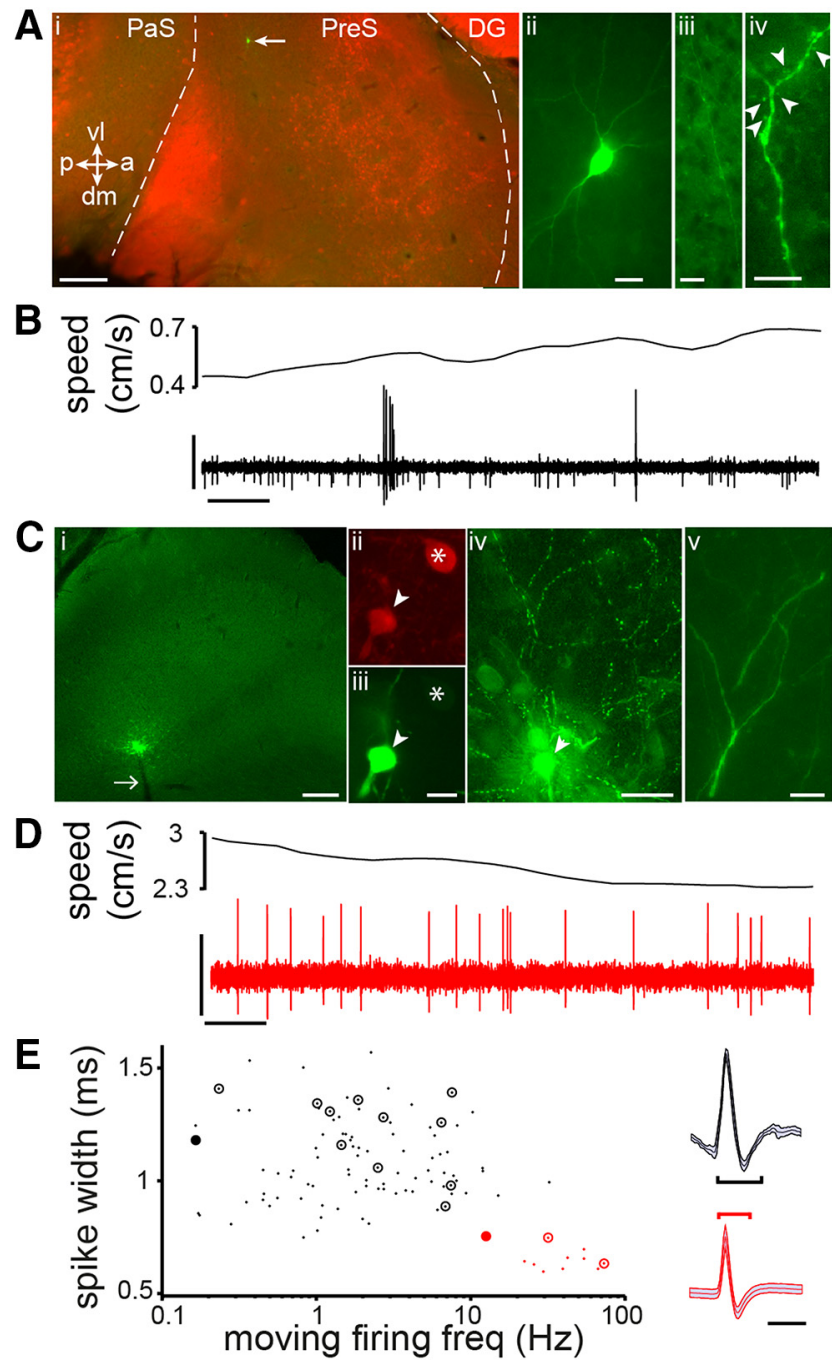

Figure 1. Classification of RS and FS cells in the presubiculum. $\boldsymbol{A}$, Recovered RS neuron (green, arrow) in the superficial layers of presubiculum (i), demarcated (dashed lines) by calbindin staining (red) in this tangentially cut section (orientation: vl, ventrolateral; dm, dorsomedial; $p$, posterior; a, anterior). Note typical pyramidal morphology (ii), projecting axon (iii), and spiny dendrites (iv, arrowheads indicate spines). PaS, Parasubiculum; PreS, presubiculum; $D G$, dentate gyrus. $B$, Speed of the animal (top trace) and APs (bottom trace, high-pass filtered) of the neuron shown in $A$. C, Recovered FS neuron (green site) in the deep layers of the presubiculum (i; parasagittal section; white arrow, electrode track), immunopositive for parvalbumin (ii, iii, arrowhead, soma from labeled cell; * ${ }^{*}$ earby parvalbumin-positive soma), with dense local axon arborization (iv) and nonspiny dendrites (v). $\boldsymbol{D}$, As in $\boldsymbol{B}$, note higher firing rate. $\boldsymbol{E}$, FS cells (red; $n=12$ ) and RS cells (black; $n=93$ ) classified based on spike width (on right, mean \pm SD from example cells in $\boldsymbol{A}-\boldsymbol{D}$, with measured spike widths indicated) and firing rate during movement $(>2 \mathrm{~cm} / \mathrm{s}$ ). Identified cells, circled; filled circles, example cells from $\boldsymbol{A}-\boldsymbol{D}$. Scale bars:Ai, $0.2 \mathrm{~mm}$, Aii-Aiii, $20 \mu \mathrm{m}$, Aiv, $10 \mu \mathrm{m} ; \boldsymbol{B}, 2 \mathrm{mV}, 0.1 \mathrm{~s} ; \boldsymbol{C}$, $0.2 \mathrm{~mm}$, Cii-Ciii, $10 \mu \mathrm{m}$, Civ, $50 \mu \mathrm{m}, \boldsymbol{C V}, 10 \mu \mathrm{m} ; \boldsymbol{D}, 1 \mathrm{mV}, 0.1 \mathrm{~s} ; \boldsymbol{E}, 1 \mathrm{~ms}$.

which the animal sampled all 36 HD bins. The statistical significance of the observed HD tuning was calculated using a shuffling procedure. Interestingly, when we plotted the HDI values of all RS cells that passed this criterion, the distribution appeared to be bimodal ( $p=0.001$, Hartigan's dip test, dip $=0.06, n=112$ ), with a narrow range of "strong HD" cells (HDI > 0.8, $n=30 ; p<$ 0.05 , shuffling test, FDR corrected; Fig. $2 D)$ and a wider range of “moderate HD" cells ( $n=41 ; p<0.05$, shuffling test, FDR corrected; Fig. $2 E$ ). The two classes showed significantly different spike widths (strong HD cells, median 0.42 ms; moderate HD cells, median $0.50 \mathrm{~ms} ; p=0.006$, Wilcoxon rank-sum test). The
A
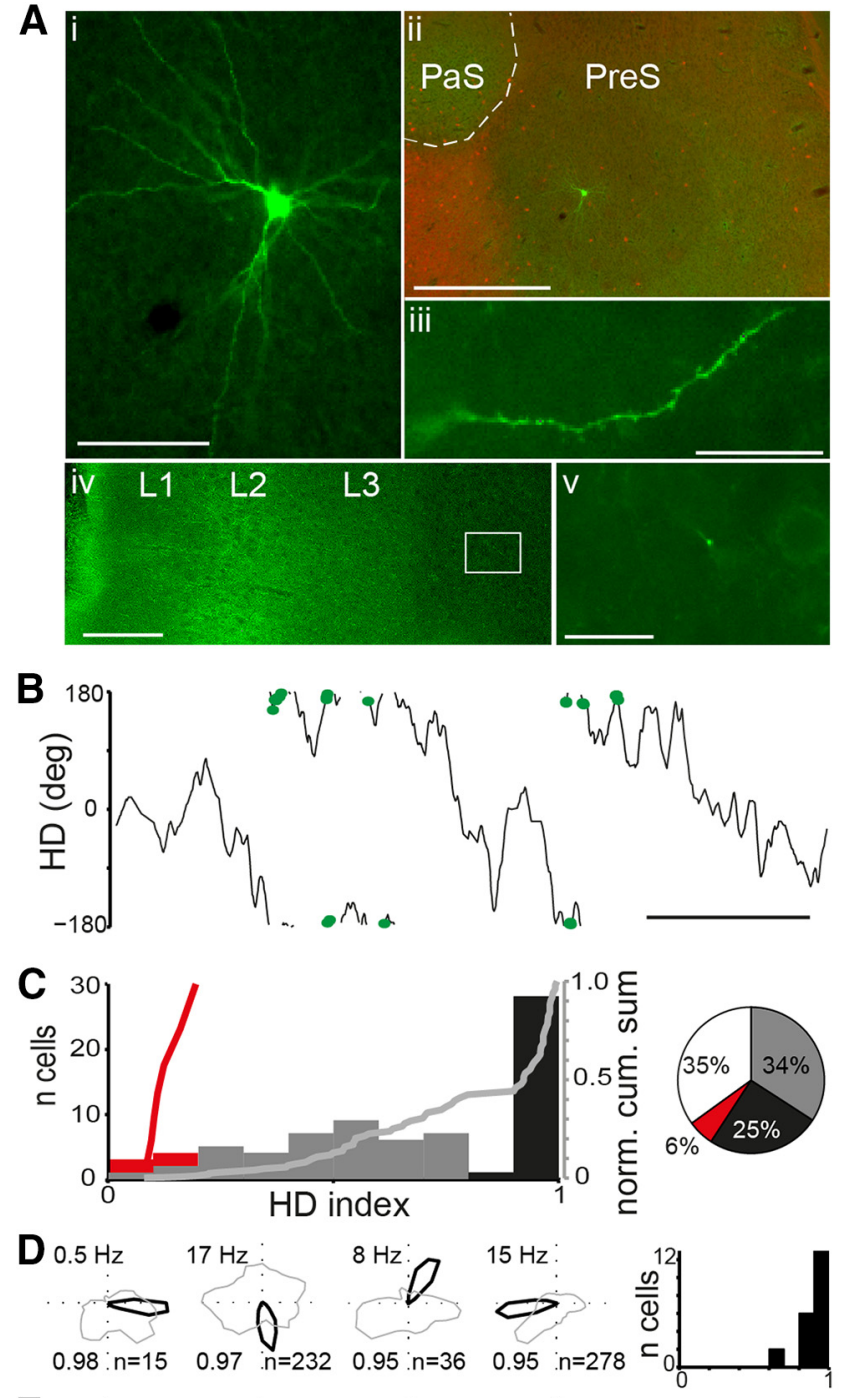

E 9
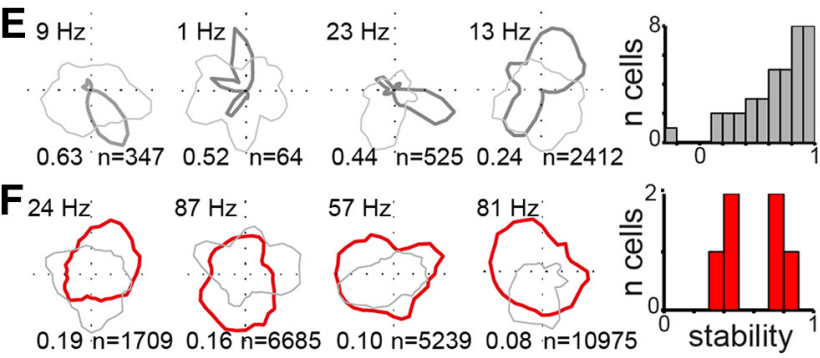

Figure 2. HD-modulated firing patterns. A, Recovered HD RS cell (green) with pyramidal morphology (i), located in layer 3 of the presubiculum (ii; tangentially cut section; red, calbindin staining), extended spiny dendrites (iii) into layer 1 and an axon into MEC (iv), where boutons could be discerned (v). $\boldsymbol{B}$, The cell fired APs (black dots) strongly modulated by HD (gray line). Scale bar, $5 \mathrm{~s}$. C, Histogram of HD tuning for all recorded cells that displayed significantly HD-modulated firing ( $n=81$ cells). The HDI value of 0.8 , where a plateau can be seen in the normalized cumulative sum ("norm. cum. sum", light gray line for RS), was chosen as the point to distinguish strong (black) from moderate (gray) HDmodulated RS cells. FS cells (red) were weakly HD modulated. $\boldsymbol{D}-\boldsymbol{F}$, Firing rates from example RS cells representing strong ( $\boldsymbol{D}$; black lines; cell in $\boldsymbol{A}, \boldsymbol{B}$ is on far right) and moderate HD cells ( $\boldsymbol{E}$, dark gray lines), and $F S$ cells $(\boldsymbol{F}$, red lines). Light gray lines indicate occupancy. Numbers indicate peak firing rate (top left), HDI (bottom left), and number of recorded APs (bottom right). Histograms on right indicate stability, defined as the correlation between the HD tuning curves from the first and second half of the recording, for all cells where the rat sampled all HD bins in each half of the recording. Scale bars: $\boldsymbol{A i}, 100$ $\mu \mathrm{m}$, Aii, $500 \mu \mathrm{m}$, Aiii, Av, $20 \mu \mathrm{m}$, Aiv, $200 \mu \mathrm{m} ; \boldsymbol{B}, 5 \mathrm{~s}$. 

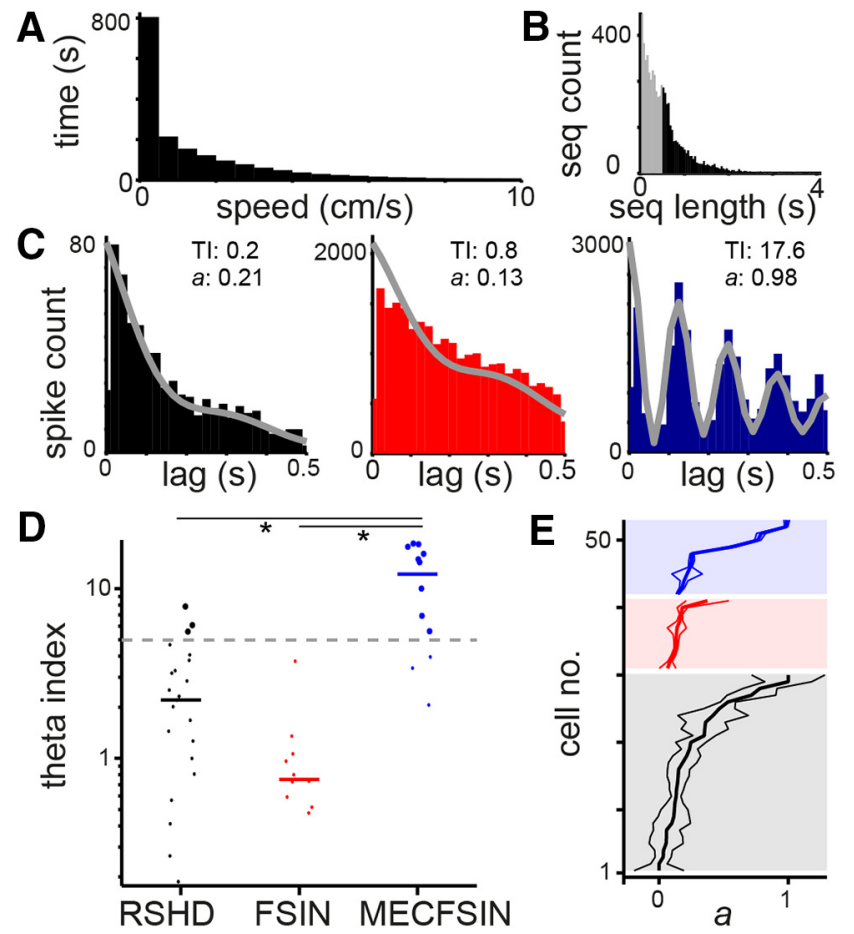

Figure 3. Cells in the presubiculum show weak theta rhythmicity. $\boldsymbol{A}$, Distribution of speeds for all recordings. $\boldsymbol{B}$, Distribution of movement sequences (seq); theta analysis was only performed on sequences (black) in which the rat moved continuously for $>0.5 \mathrm{~s}$. C, Spike autocorrellograms show little theta rhythmicity for a representative HD RS (left) and FS cell (middle), but strong theta rhythmicity for a FS cell in the MEC (right). Tl indicates theta index; a quantifies rhythmicity based on a MLE parametric model fit (gray lines; see Materials and Methods). D, Theta-modulated cells (index $>5$, gray dashed line) are indicated as large dots. For each cell class, horizontal bars indicate medians. Cell classes were not from a single distribution ( $p<1 * 10^{-5}$, Kruskal-Wallis test). ${ }^{*} p<0.01$, post hoc Dunn-Sidak test, indicating a significant difference between MEC FS cells (MECFSIN) and presubicular HD-tuned RS cells (RSHD) and FS cells (FSIN). $E$, Distribution of $a$ for all cells recorded during periods in which the rat moved sufficiently. For each class (color-coded as in C), cells were ordered by their $a$ value; values are plotted as a thick line, with thin lines indicating $95 \%$ confidence intervals. Note narrow confidence intervals, indicating that the $a$ values were reliable estimates of theta rhythmicity in these recordings.

final class of HD-modulated cells consisted, unexpectedly, of FS cells ( $n=7 ; p<0.05$, shuffling test, FDR corrected) with decidedly weak HD tuning and limited stability as evidenced by low correlations of tuning curves from the first versus second half of each recording (median $r=0.5$ for 6 cells with sufficient coverage in both halves of the recording; Fig. $2 F$ ). Overall, the firing of a majority of tested cells was significantly HD modulated $(n=78$ significant of 123 cells), consistent with previous observations (Boccara et al., 2010).

Firing did not appear to be strongly modulated by running speed, as quantified by a speed index (Sun et al., 2015) in which a value of 1 indicates no modulation (median speed index 1.07 for FS cells, $0 / 12$ significant; 1.03 for moderate HD cells, $1 / 67$ significant; 1.17 for strong HD cells, 6/25 significant).

During active movement, the hippocampal formation generally displays prominent theta oscillations $(4-12 \mathrm{~Hz})$, which are likely to play an important role in the temporal organization of spatial information (Buzsáki and Moser, 2013). In agreement with previous recordings from unidentified cells (Boccara et al., 2010), we find that, during periods of movement (see Materials and Methods; Fig. $3 A, B$ ), most RS cells showed very little thetarhythmic firing, as evidenced by relatively flat spike autocorrellograms (Fig. 3C). Only four of 30 RS cells with sufficient movement passed the threshold for theta rhythmicity (theta index $>5$; median theta index 2.0), matching previous reports (Taube et al., 1990; Sharp, 1996). Considering only RS cells with significant HD tuning (median theta index 2.2), only three cells of 23 passed the threshold (Fig. $3 D$ ), suggesting that mechanisms underlying $\mathrm{HD}$ tuning in the presubiculum are unlikely to rely on theta rhythmicity (Sharp, 1996; Boccara et al., 2010).

Surprisingly, we also found that not a single cell of 11 FS cells showed theta-rhythmic firing (Fig. 3C,D). Such weak theta rhythmicity is in strong contrast to the FS cells that we recorded in the superficial layers of the MEC, where 9/12 juxtacellularly recorded cells fired with strong theta rhythmicity (Fig. $3 C, D$ ), suggesting that the lack of theta rhythmicity in presubicular FS cells is unlikely to be an effect of our recording method. Furthermore, quantification of the theta rhythmicity using a MLE approach (Fig. 3C,E), which is less sensitive to biases arising from recording length and firing rates (Climer et al., 2015), confirmed the low theta rhythmicity of FS cells (median $a=0.14$ ). Importantly, the $95 \%$ confidence intervals for the rhythmicity fit to the data delineated a relatively narrow range (Fig. $3 E$ ), indicating that theta rhythmicity was indeed unlikely, rather than being a result of our limited recordings. The same measures also confirmed the low theta rhythmicity of HD-modulated RS cells (median $a=$ 0.14 ) and the stronger theta rhythmicity of the MEC FS cells (median $a=0.25$ ).

\section{Discussion}

We have shown that HD cells have a pyramidal morphology with apical dendrites branching in layer 1 and some axons reaching MEC. The fact that we saw so few axonal projections is likely a result of the fact that we labeled the cells in a freely moving animal, resulting in less complete filling of the cells compared with anesthetized animals. However, our data do indicate that at least a subset of the MECprojecting pyramidal cells in layer 3 of the presubiculum is HD. This is consistent with a role for propagating HD input from the thalamus (Goodridge and Taube, 1997; Peyrache et al., 2015) to the MEC, possibly providing excitatory HD-tuned input to spatially tuned cells there (Winter et al., 2015).

Our demonstration, based on identified cells, that pyramidal cells and interneurons in the presubiculum can be distinguished based on spike shape and firing rate during movement should prove very useful for future extracellular studies. Such studies, using longer recording times, may also elucidate the nature of the weak HD tuning that we observed in FS interneurons. It is tempting to speculate that FS interneurons in the presubiculum may also play a role in the processing of HD information: their weak but significant HD tuning could suggest a lateral-inhibition-type connectivity, consistent with an attractor model in which the cells signaling the current direction inhibit all other cells disynaptically.

It should be pointed out that the limited recording times meant that we were not able to investigate spatial tuning of the recorded cells, so some recorded HD cells may in fact be conjunctive placeby-direction (Cacucci et al., 2004) or grid-by-direction (Boccara et al., 2010) cells. Regardless of what the spatial tuning may be, our method was sufficient to observe clear HD tuning (Fig. 2), with the overall percentage of significant tuning very similar to a previous report using extracellular methods (Boccara et al., 2010).

Finally, the weak theta rhythmicity of pyramidal cells in the presubiculum, consistent with previous reports for putative principal cells (Taube et al., 1990; Sharp, 1996; Boccara et al., 2010), suggests that communication between the presubiculum and MEC is not strongly organized on a theta timescale. This is consistent with the fact that path integration, presumably relying on 
the integration of HD and theta-coded speed information (McNaughton et al., 2006), does not appear to require the presubiculum (Bett et al., 2012), although other parts of the HD system have been implicated (Cooper and Mizumori, 1999; Frohardt et al., 2006; Valerio and Taube, 2012) and indeed the presubiculum does contain velocity-encoding cells (Sharp, 1996). The reported presence of grid and border cells in the presubiculum (Boccara et al., 2010) suggests that some speed-coded information must be integrated here, perhaps independently of theta (Yartsev et al., 2011) or mediated by a small subgroup of theta-rhythmic cells (Cacucci et al., 2004). One intriguing possibility is that theta and $\mathrm{HD}$ signaling are combined presynaptic to the presubiculum in anterior thalamic nuclei (Tsanov et al., 2011; Welday et al., 2011). The dendritic morphology of the recovered pyramidal cells suggests that presubicular HD cells could receive input from these areas (van Groen and Wyss, 1995). Indeed, we do see some thetarhythmic cells (Fig. 3D,E), but there was no obvious difference in morphology between theta-rhythmic and nonrhythmic cells. Therefore, the mechanism for this theta-rhythmic firing remains unclear, particularly given the fact that none of the FS cells fired in a theta-rhythmic manner. This is surprising given the proposed role of parvalbumin-positive FS interneurons in the generation of theta oscillations in other areas of the hippocampal formation (Stark et al., 2013). It remains for future investigations to more fully address the role of FS interneurons, as well as other types of interneurons, in the presubicular microcircuitry.

\section{References}

Bett D, Wood ER, Dudchenko PA (2012) The postsubiculum is necessary for spatial alternation but not for homing by path integration. Behav Neurosci 126:237-248. CrossRef Medline

Boccara CN, Sargolini F, Thoresen VH, Solstad T, Witter MP, Moser EI, Moser MB (2010) Grid cells in pre- and parasubiculum. Nat Neurosci 13:987-994. CrossRef Medline

Buzsáki G, Moser EI (2013) Memory, navigation and theta rhythm in the hippocampal-entorhinal system. Nat Neurosci 16:130-138. CrossRef Medline

Cacucci F, Lever C, Wills TJ, Burgess N, O’Keefe J (2004) Theta-modulated place-by-direction cells in the hippocampal formation in the rat. J Neurosci 24:8265-8277. CrossRef Medline

Climer JR, DiTullio R, Newman EL, Hasselmo ME, Eden UT (2015) Examination of rhythmicity of extracellularly recorded neurons in the entorhinal cortex. Hippocampus 25:460-473. CrossRef Medline

Cooper BG, Mizumori SJ (1999) Retrosplenial cortex inactivation selectively impairs navigation in darkness. Neuroreport 10:625-630. CrossRef Medline

Frohardt RJ, Bassett JP, Taube JS (2006) Path integration and lesions within the head direction cell circuit: comparison between the roles of the anterodorsal thalamus and dorsal tegmental nucleus. Behav Neurosci 120: 135-149. CrossRef Medline

Goodridge JP, Taube JS (1997) Interaction between the postsubiculum and anterior thalamus in the generation of head direction cell activity. J Neurosci 17:9315-9330. Medline

Hartigan JA, Hartigan PM (1985) The dip test of unimodality. Annals of Statistics 13:70-84. CrossRef

Herfst L, Burgalossi A, Haskic K, Tukker JJ, Schmidt M, Brecht M (2012) Friction-based stabilization of juxtacellular recordings in freely moving rats. J Neurophysiol 108:697-707. CrossRef Medline

Kerr KM, Agster KL, Furtak SC, Burwell RD (2007) Functional neuroanat- omy of the parahippocampal region: the lateral and medial entorhinal areas. Hippocampus 17:697-708. CrossRef Medline

Knierim JJ, Zhang K (2012) Attractor dynamics of spatially correlated neural activity in the limbic system. Annu Rev Neurosci 35:267-285. CrossRef Medline

McNaughton BL, Battaglia FP, Jensen O, Moser EI, Moser MB (2006) Path integration and the neural basis of the "cognitive map." Nat Rev Neurosci 7:663-678.

Peyrache A, Lacroix MM, Petersen PC, Buzsáki G (2015) Internally organized mechanisms of the head direction sense. Nat Neurosci 18:569-575. CrossRef Medline

Raudies F, Brandon MP, William Chapman GW, Hasselmo ME (2015) Head direction is coded more strongly than movement direction in a population of entorhinal neurons. Brain Res 1621:355-367. CrossRef Medline

Ray S, Naumann R, Burgalossi A, Tang Q, Schmidt H, Brecht M (2014) Grid-layout and theta-modulation of layer 2 pyramidal neurons in medial entorhinal cortex. Science 343:891-896. CrossRef Medline

Schwaller B, Dick J, Dhoot G, Carroll S, Vrbova G, Nicotera P, Pette D, Wyss A, Bluethmann H, Hunziker W, Celio MR (1999) Prolonged contraction-relaxation cycle of fast-twitch muscles in parvalbumin knockout mice. Am J Physiol 276:C395-C403. Medline

Sharp PE (1996) Multiple spatial/behavioral correlates for cells in the rat postsubiculum: multiple regression analysis and comparison to other hippocampal areas. Cereb Cortex 6:238-259. CrossRef Medline

Stark E, Eichler R, Roux L, Fujisawa S, Rotstein HG, Buzsáki G (2013) Inhibition-induced theta resonance in cortical circuits. Neuron 80: 1263-1276. CrossRef Medline

Sun C, Kitamura T, Yamamoto J, Martin J, Pignatelli M, Kitch LJ, Schnitzer MJ, Tonegawa S (2015) Distinct speed dependence of entorhinal island and ocean cells, including respective grid cells. Proc Natl Acad Sci U S A 112:9466-9471. CrossRef Medline

Tang Q, Brecht M, Burgalossi A (2014) Juxtacellular recording and morphological identification of single neurons in freely moving rats. Nat Protoc 9:2369-2381. CrossRef Medline

Taube JS (1995) Head direction cells recorded in the anterior thalamic nuclei of freely moving rats. J Neurosci 15:70-86. Medline

Taube JS, Muller RU, Ranck JB Jr (1990) Head-direction cells recorded from the postsubiculum in freely moving rats. I. Description and quantitative analysis. J Neurosci 10:420-435. Medline

Tsanov M, Chah E, Vann SD, Reilly RB, Erichsen JT, Aggleton JP, O’Mara SM (2011) Theta-modulated head direction cells in the rat anterior thalamus. J Neurosci 31:9489-9502. CrossRef Medline

Valerio S, Taube JS (2012) Path integration: how the head direction signal maintains and corrects spatial orientation. Nat Neurosci 15:1445-1453. CrossRef Medline

van Groen T, Wyss JM (1990a) The postsubicular cortex in the rat: characterization of the fourth region of the subicular cortex and its connections. Brain Res 529:165-177. CrossRef Medline

van Groen T, Wyss JM (1990b) The connections of presubiculum and parasubiculum in the rat. Brain Res 518:227-243. CrossRef Medline

van Groen T, Wyss JM (1995) Projections from the anterodorsal and anteroventral nucleus of the thalamus to the limbic cortex in the rat. J Comp Neurol 358:584-604. CrossRef Medline

Welday AC, Shlifer IG, Bloom ML, Zhang K, Blair HT (2011) Cosine directional tuning of theta cell burst frequencies: evidence for spatial coding by oscillatory interference. J Neurosci 31:16157-16176. CrossRef Medline

Winter SS, Clark BJ, Taube JS (2015) Spatial navigation. Disruption of the head direction cell network impairs the parahippocampal grid cell signal. Science 347:870-874. CrossRef Medline

Yartsev MM, Witter MP, Ulanovsky N (2011) Grid cells without theta oscillations in the entorhinal cortex of bats. Nature 479:103-107. CrossRef Medline 